\title{
Dielectric relaxation studies in chloral and ethyltrichloroacetate
}

\author{
Santosil Kumar Srivastava and Shyam Lal SRivastava \\ Physics Department, Allahabad University, Allahabad 211002
}

\begin{abstract}
Pcrmittivity and dielectric loss measurements have been carried out on pure liquid chloral and ethyltrichloroacetate uplo $60 \mathrm{GHz}$ frequencies. For chloral a symmetrical Cole-Cole arc is obtained and the data is analysed in terms of two relaxation times representıng overall and intramolecular rolations. For ethyltrichloroacetate a Debye behaviour with an indication for another dispersion after microwave regon is obtained.
\end{abstract}

\section{INTROIUUCTION}

Dielectric absorption measurements at microwave frequencies have provided an effective means for studying molecular structure in liquids and solutions ${ }^{1,2}$. The present paper describes the results of dielectric relaxation studies carried out on two pure liquids chloral $\left(\mathrm{CCl}_{3} \mathrm{CHO}\right)$ and ethyltrichloroacetate $\left(\mathrm{CCl}_{3} \mathrm{COOC}_{2} \mathrm{H}_{3}\right)$ at a number of microwave frequencies and is a part of general study carried out on some trichloro group aliphatic compounds.

\section{EXPFRIMUNTAI,}

Permittivity $\left(\varepsilon^{\prime}\right)$ and dielectric loss $\left(\varepsilon^{\prime \prime}\right)$ measurements have been carried out on chloral at following frequencies and temperatures. At $10^{\circ} \mathrm{C}$ the frequencies are 3.5, 9.8 and $23.5 \mathrm{GHz}$ : at $25^{\circ} \mathrm{C}$ these are $3.5,9.8,23.5,36.1$ and $60.2 \mathrm{GHz}$, and dt $41^{\circ} \mathrm{C}$ the frequencies are $3.5,9.8,23.5$ and $36.1 \mathrm{GHz}$. Similarly for ethyltichloroacetate the permittivity and dielectric loss measurements have been carried out at $2.4,4.2,9.9$, and $24.6 \mathrm{GHz}$ at $10^{\circ} \mathrm{C}$; at 1.8 , $2.4,9.8,24.6,36.1$, and $60.2 \mathrm{GHz}$ at $30^{\circ} \mathrm{C}$, and at $2.4,4.2,9.8,24.6$, and 36.1 $\mathrm{GHz}$ at $50^{\circ} \mathrm{C}$. The static permittivity $\left(\varepsilon_{1}\right)$ and refractive index $(\mathrm{n})$ have also been measured.

Transmission line and free space techniques are used for determisation of permittivity and dielectric loss at various microwave frequencies. In the frequency range of 1.8 to $4.2 \mathrm{GHz}$ and at $36 \mathrm{GHz}$ PoLEY's $\mathrm{s}^{3}$ method is utilised for determination of permittivity and dielectric loss. At about 9 and $24 \mathrm{GHz}$ SuRBur's ${ }^{4}$ method is used. Measurements at $60 \mathrm{GHz}$ have been done using mucrowave interferometric technique". Static permittivity measurements have 
been done from appiratus based on heterodyne buit method and refractive index is measured from an Abbe's refractometer. Details of the experimental set-ups and procedures have been described in the previous publications ${ }^{6}$.

\section{Analxsis (2) DaIt}

For a system having single relaxation time Drbyr ${ }^{-}$gate following well known relation between complex permittivity $\left(\varepsilon^{*}\right)$ and relaxation time $(\tau)$

or

$$
\varepsilon^{*}=\varepsilon_{\infty}+\frac{\varepsilon_{0}-\varepsilon_{\infty}}{1+j \omega \tau}
$$

and

$$
\begin{array}{cc}
\varepsilon^{\prime}-\varepsilon_{\infty} & 1 \\
\varepsilon_{0}-\varepsilon_{\infty} & 1+(\omega \tau)^{2} \\
\varepsilon^{\prime \prime} & =\frac{\omega \tau}{1+(\omega \tau)^{\prime \prime}}
\end{array}
$$

Here $\omega$ is angular frequency. The plot of $\varepsilon^{\prime \prime}$ against $\varepsilon^{\prime}$ in this case is a semicircle. However, a number of cases are also obtained where relaxation times are distributed symmetrically along a most probable value. $\varepsilon^{\prime \prime}$ vs $\varepsilon^{\prime}$ curve in this case is an arc of a circk and falls below the Debye semucircle. COLE and COl: $F^{\circledR}$ have suggested following empirical relation to account for the observed value of complex permittivity

$$
\varepsilon^{*}=\varepsilon_{\infty}+\begin{gathered}
\varepsilon_{11}-\varepsilon_{\infty} \\
1+(j, \nu \tau)^{*}
\end{gathered}
$$

where $\alpha$ signities the distribution of relaxation tumes and is generally known as distribution parameter. On rationalizing eq. (3) following relations are obtained

$$
\frac{\varepsilon^{\prime}-\varepsilon_{\infty}}{\varepsilon_{0}-\varepsilon_{\infty}}=\frac{1+(\omega \tau)^{\prime \prime} \sin (\alpha \pi / 2)}{1+(\omega \tau)^{2(1-\alpha)}+2(\omega \tau)^{1}+\sin (\alpha \tau / 2)}
$$

and

$$
\frac{\varepsilon^{\prime \prime} \infty}{\varepsilon_{n}-\varepsilon_{\infty}}=\frac{(\omega \tau)^{1-\alpha} \cos (\alpha \pi / 2)}{1+(\omega \tau)^{2(1-\alpha)}+2(\omega \tau)^{1-\alpha} \sin (\alpha \pi / 2)}
$$

From the available standard techniques the values of relaxation time and distribution parameter are easily determined for a system following Cole-Cole or Debye arc plot. 
We have also determined the relaxation times $\left(\tau_{1}\right)$ and $\left(\tau_{2}\right)$, associated and $\tau_{2}$ from eqs. (5a) and (5b) a graphical method similar to that of follows the Bubo's" equations given as

$$
\frac{\varepsilon^{\prime}-\varepsilon_{\infty}}{\varepsilon_{11}-\varepsilon_{\infty}}=\frac{C_{1}}{1+\left(\omega \tau_{1}\right)^{2}}+\frac{C_{2}}{1+\left(\omega \tau_{2}\right)^{2}}
$$

and

$$
\frac{\varepsilon^{\prime \prime}}{\varepsilon_{10}-\varepsilon_{\infty}}=\frac{C_{1} \omega \tau_{1}}{1+\left(\omega \tau_{1}\right)^{2}}+\frac{C_{2} \omega \tau_{2}}{1+\left(\omega \tau_{2}\right)^{2}}
$$

With $C_{1}+C_{22}=1$.

$C_{1}$ and $C_{2}$ are the strength of each relaxation process. In order to determine $\tau_{1}$ and to from eqs. (5a) and (5b) a graphical method similar to that of Bualtacharva et al. ${ }^{10}$ has been used. The final equation comes out to be

$$
(1-A) /(B \omega)=\left(\tau_{1}+\tau_{2}\right)-(A \omega) /(B) . \quad\left(\tau_{1} \tau_{2}\right)
$$

where $A=\frac{\varepsilon^{\prime}-\varepsilon_{\infty}}{\varepsilon_{0}-\varepsilon_{\infty}}$ and $B=\left(\varepsilon^{\prime \prime}\right) /\left(\varepsilon_{0}-\varepsilon_{\infty}\right)$. so when $(1-A) /(B \omega)$ is piotted against $(A \omega) /(B)$ a straight line of slope $\left(\tau_{1}, \tau_{2}\right)$ and intercept $\left(\tau_{1}+\tau_{2}\right)$ is obtained from which $\tau_{1}$ and $\tau_{2}$ are determined.

For the case of chloral. assuming FroHLICH ${ }^{11}$ type distribution funclion, two limiting relaxation times $\tau_{1}$ and $\tau_{2}$ have been determined following Hiritsi's:- method. The final equations are

$$
\begin{aligned}
& \tau_{1}=\tau \cdot \mathrm{e}^{-\mathrm{A} / 2} \\
& \tau_{2}=\tau \cdot \mathrm{e}^{\mathrm{A} / 2}
\end{aligned}
$$

where $\tau$ is Cole-Cole average time and $A$ is a function given by

$$
\tan \frac{(1-\alpha) \pi}{4}=\frac{4}{A} \tan ^{-1}\left(\tanh \frac{A}{4}\right)
$$

\section{RFsults AND Discussion}

\section{(a) For Chloral}

From the measured values of $\varepsilon^{\prime}, \varepsilon^{\prime \prime}, \varepsilon_{0}$ and $\varepsilon_{\infty}\left(=n^{\prime \prime}\right)$ the normalized Cole-Cole curve is plotted [plot of $\left(\varepsilon^{\prime}-\varepsilon_{\infty}\right) /\left(\varepsilon_{0}-\varepsilon_{\infty}\right)$ against $\left(\varepsilon^{\prime \prime}\right)$ । $\left.\left(\varepsilon_{0}-\varepsilon_{\infty}\right)\right]$. The points for the normalized plot from the observed data 
for all the three temperatures are shown in Fig. 1. The values of relaxation and distribution parameter calculated from plot of different ColeCole are for the three temperatures are given in table 1. It seems from

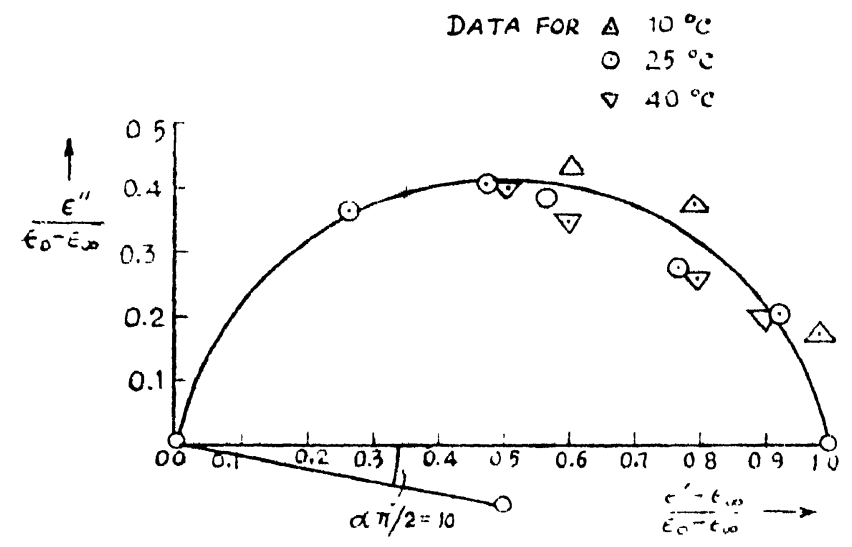

Fig. 1. Normalized plot for chloral (nuic) for $\alpha=0.11$

Table 1 that the temperature dependence of the relaxation time and distribution parameter are not very clearly revealed in the temperature region and the variations found are well within the prohable errors of the parameters involved. Therefore, a single average value of these parameters may explain our experimental data for the three temperatures The average value of distribution parameter so obtained $(\alpha=0.11)$ is then used to draw a Cilecole arc passing through atl the experimental points of Fig. 1. It is evident from

Table 1. Values of relaxation time and distribution parameter for chloral (pure) as obtained by various method

\begin{tabular}{|c|c|c|c|c|c|c|}
\hline \multirow{4}{*}{$\begin{array}{c}\text { Temperature } \\
\text { 'C: }\end{array}$} & \multicolumn{2}{|c|}{ From Cole-Cole Analysis } & \multicolumn{2}{|c|}{ From Budo's Analysis } & \multicolumn{2}{|c|}{$\begin{array}{c}\text { From Higasi } \\
\text { Analysis } \\
. . . .\end{array}$} \\
\hline & & & & $\cdot$ & & \\
\hline & Relaxation & Distribution & $\tau_{1}$ & $\tau:$ & $\tau_{1}$ & $\tau: 2$ \\
\hline & $\begin{array}{l}\operatorname{time}(\tau) \\
\times 10^{\prime 2} \mathrm{sec}\end{array}$ & $\begin{array}{l}\text { pirameter } \\
\qquad(\alpha)\end{array}$ & $\times 10^{\prime \prime \prime}$ sec & $\times 10^{\prime} \mathrm{sec}$ & $\times 10^{12} \mathrm{sec}$ & $\times 10^{12} \mathrm{sec}$ \\
\hline 10 & 7.1 & 0.08 & & & & \\
\hline 25 & 6.1 & 0.13 & & & & \\
\hline 40 & 5.1 & 0.14 & & & & \\
\hline Avorage & $6.4 \pm 0.5$ & $0.11 \pm 003$ & $23.5 \pm 4$ & $3.1 \pm 2$ & 19.9 & 2.0 \\
\hline
\end{tabular}




\section{Santosh Kumar. Srivastava and Shyam Lal Srivastava}

Fig. 2 that the above curve explains all the observed points. In order to elaborate this we have drawn in Fig. 2 a theoretical dispersion and absorption curve taking the average value of the distribution parameter $a=0.11$. The curve, a plot of $\left(\varepsilon^{\prime}-\varepsilon_{-}\right) /\left(\varepsilon_{0}-\varepsilon_{\infty}\right)$ and $\left(\varepsilon^{\prime \prime}\right) /\left(\varepsilon_{0}-\varepsilon_{\infty}\right)$ against
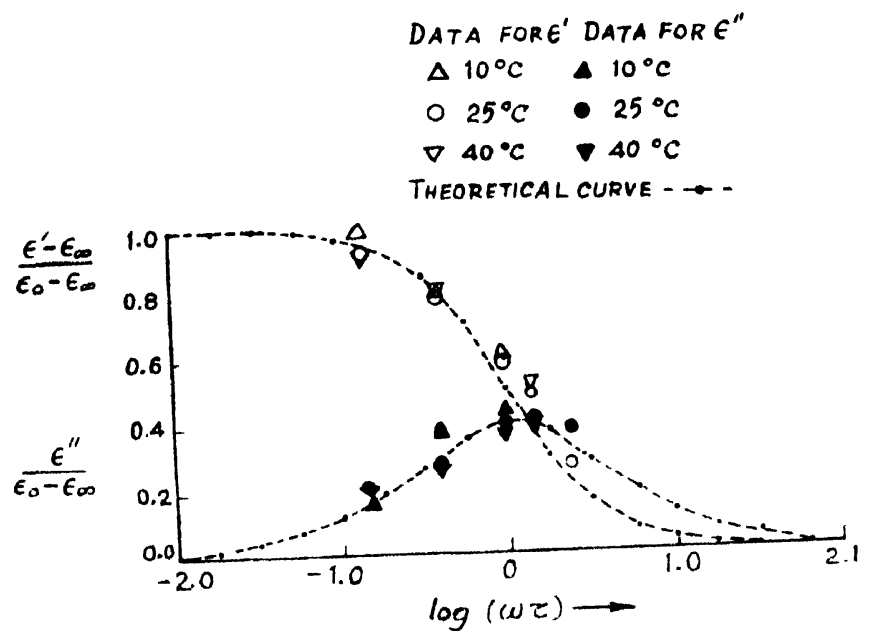

Fig. 2. Theoretical dispersion and absorption curve for $\alpha=0.11$ and experimental points for $\tau=6.4 \mathrm{p} \mathrm{sec}$.

$\log (\omega \tau)$, is easily obtained with the help of eqs. (4a and $4 b$ ). Also shown on the same curve are the points for the observed dispersion and absorption curve taking an average value of relaxation time (from table 1 as $6.4 \mathrm{p} \mathrm{sec}$ ) for all the three temperatures. It can be seen from the Fig. 2 that the theoretical curve explains satisfactorily all the observed data as the dispersion and absorption curve are scattered within $\pm 12 \%$ and $\pm 15 \%$ from the theoretical curve.

With the help of eq. (6) we have also determined two relaxalion times $\tau_{1}$ and $\tau_{2}$. Here a least square fit of the experimental data for all the three temperatures is used to determine the slope and intercept from which $\tau_{1}$ and $\tau_{2 .}$ are determined. These values are reported in table 1. Assuming Frohlich types distribution function and taking overage value of cole-cole distribution parameter, the values of $\tau_{1}$ and $\tau_{2}$ determined with the help of eqs. (7a) and 7b) are listed in table 1 . It is clear from table 1 that these two representation yicld almost same values of $\tau_{1}$ and $\tau_{2}$. The values of $\tau_{1}$ and $\tau_{: 2}$ determined from the least square fit of the experimental data are expected to be uncertain by $\pm 20 \%$ or so $^{13}$ and present graphical analysis is bound to give still large error in these parameters. However, the structure of the molecule is suggestive that $\tau_{1}$ may correspond to overall rotation of the molecule and $\tau_{2}$ to the intramolecular group rotation. The dipole bearing groups in chloral are $-\mathrm{CCl}_{3}$ and $-\mathrm{CH} 0$ and any one of them may act 
as a frame and top respectively for the probable intramolecular group rotation.

\section{(b) For Ethyltrichloroacetate}

The normalized ples points for ethyltrichloroacetate as obtained from the experimental data are shown in Fig. 3 and an avorage curve passing

$$
\begin{aligned}
& \text { DATARUKA } 10^{\circ} \mathrm{C} \\
& \therefore 30^{\circ} \mathrm{L} \\
& \text { (7) } 901 \%
\end{aligned}
$$

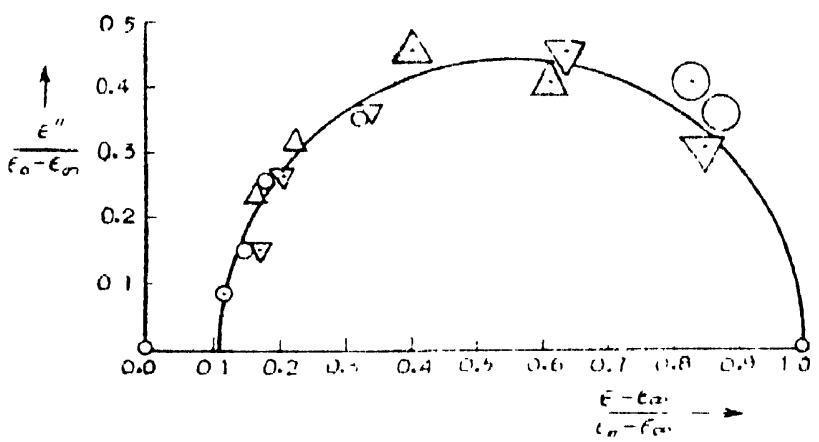

Fig. 3. Normalized plot for ethyltrichloroacetate (pure).

through all the experimental points is drawn. The nature of the curve seems to be a Debye semicircular arc. It is seen from the flgure that high frequency limiting permittivity, to be called as $\varepsilon_{1 \infty}$ (where subscript 1 refers to first dispersion region), is significantly different from $\varepsilon_{\infty}\left(=n^{2}\right)$. The correct estimate of $\varepsilon_{1}$ has been obtained from the intercept of $\varepsilon^{\prime}$ vs $\varepsilon^{\prime \prime} / \lambda$ curve, where $\lambda$ is the wavelength of the microwave radiation. The utility of millimeter wave measurements in accurate determination of $\varepsilon_{1_{\infty}}$ has been clearly demonstrated by GARI, and $S_{M Y T H^{11}}$ and in the present case millimeter wave measurement greatly facilitates the correct determination of $\varepsilon_{1}$ value.

A semicircular Debye curve seems to explain the data adequately well at all the three temperatures with appreciable difference bitween $\varepsilon_{1}$ and $\varepsilon_{\infty}\left(=n^{2}\right)$ values. Such a difference is generally thought as that atleast one dispersion region exists leading to considerable ahsorption between Debye dispersion region and optical region. HILI. ${ }^{15}$ has considered the possible origin of such an absorption in rigid polar molecules regarding individual molecule to be confined in a cage formed by neighbour molecules. 
As in the case of chloral it is not of much significance to draw three differnt Debye curves for the three temperatures. A single value of relaxition can explain the data satisfactorily within the probable errors of the parameters involved. The value of relaxation time obtained from the average Debyc curve of Fig. 3 comes out to be $34 \mathrm{p}$ sec. We have plotted a theoretical Debye dispersion and obsorption curve, from eys. (2a) and (2b), in Fig. 4. Also shown in the same figure are the points for experimentally

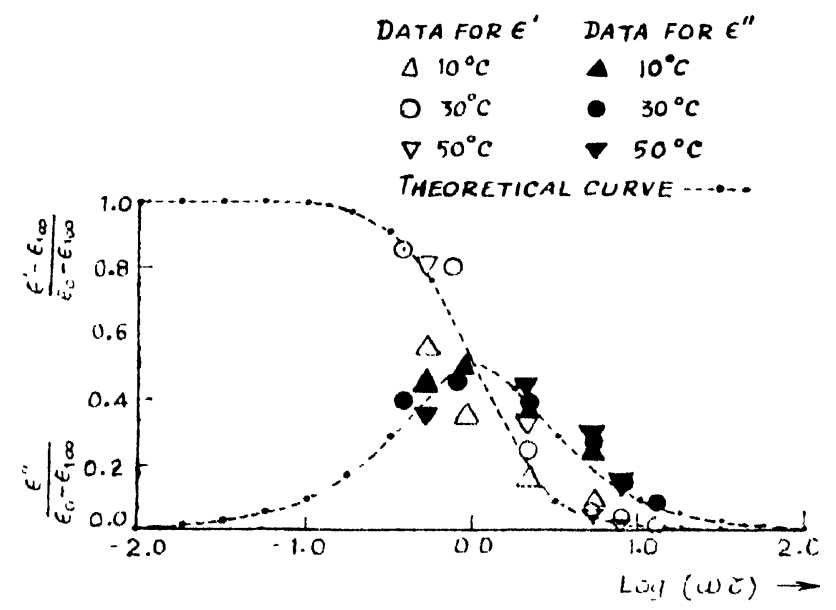

Fig. 4. Debye dispersion and absorption curve and experimental points for $\tau--34 \mathrm{p}$ sec

observed dispersion and absorption curve [plot of $\left(\varepsilon^{\prime}-\varepsilon_{1_{\infty}}\right)^{\prime}\left(\varepsilon_{11}-\varepsilon_{\varepsilon_{\infty}}\right)$ and $\varepsilon^{\prime \prime} /\left(\varepsilon_{0}-\varepsilon_{1}\right)$ against $\left.\operatorname{lng} \omega \tau\right]$ taking above average value of relaxation time. As from Fig. 4 the theonetical curve seems to explain satisfactorily the data for all the three temperatures. Table 2 gives values of relaxation time

Table 2. Relaxation time and wher parameters for ethyltrichloroacetate (pure)

\begin{tabular}{cccc}
$\begin{array}{c}\text { Temperature } \\
{ }^{\circ} \mathrm{C}\end{array}$ & $\begin{array}{c}\text { Relaxation time }(\tau) \\
\times 10^{\prime 2} \mathrm{sec}\end{array}$ & $\varepsilon_{1 \infty}$ & $\mathrm{n}^{3}$ \\
\hline 10 & 44.1 & 2.65 & 2.111 \\
30 & 29.9 & 2.75 & 2.091 \\
50 & 28.4 & 2.90 & 2.060 \\
Average & $34 \pm 7$ & & \\
\hline
\end{tabular}

obtained from the three temperature data and the average value taken thereof. Also given in the table are the values of $\varepsilon_{\infty}$ and $\varepsilon_{1}$. It seems 
that ethyltrichloroacetate moleculc behaves as a rigid polar molecule and hence the probability of intramolecular group rotation is ruled out. However, there is a clear indication for another dispersion in infra and far infra red regions.

\section{Al KN(WWI.I.IXII:AII:N IS}

The authors are thankful to Professor Krishnaji for his constant interest, valuable help and discussions in the present work. Thanks are also due to Professor C. Ralnasastry, Head Physics Department, Indian Institute of Technology, Madras for allowing to use 36 and $60(3 \mathrm{~Hz}$ set-ups of his Departmnt and to Mr. V. Ramakrishna Murty for his help in measurements. S.K.S. is also thankful to Dpartment of Atomic Innrgy, Civernment of India for award of a Senior research felloship.

\section{RIFHINCES}

1 C P Smyth, Dielectric Behaviour and Structure (Megrau Hill Booh Co., New York, 1955)

2 N. E. Hill W E. Vaughan, $\Lambda$ H Price and $M$ Davies, Dielectric Properties and Molecular Bchaviour (Van Nestrand Rembild (o, London 1969)

3. J P Poley. J Appl Sc1. Res. B4 (1955; 3.37

4. W. H. Surber (Jr) J Appl. Phys. 19 (1948) 514

5. W. E. Vaughan. K. Bergmann and (. P Smyth J Phys. (hem 65(1961) 94.

6. Krishnaji and A. Mansısgh, J (hem Phys 41 (1964) 827.

7. P Dcbyc, Polar Molecules (1)uver Publishing ('o New Yorh, 1949)

8 K. S. Cole and R. H Cole. J. Chem l'hys. 9 (1941) 341.

9 A. Budo, Physık \% 39 (1938) 7(k

10. J. Bhattacharya, A Hasan. S B Roy and (; S Kastha. I Phys Soc (Japan) 28 (1970) 204

11. H. Frohlich, Iheory of Dielectrics (Oxtord University Press 1949)

12. K. Higasi, Dielectric Relaxation and Molecular Structure (Hokhatdo University, Sapparo. Japan, 196,1)

13. J. Crossley. S. Walker and S. P Tay, Adv. Mol. Relaxation Processes 6 (1974) 74.

14. S. K. Garg and C. P. Smyth, J Chem Phys 42 (1965) 1397

15. N E. Hill, Proc. Phys. Soc. (London) 82 (1963) 723 